\title{
Technical Analysis of College Psychological Crisis Management
}

\author{
Jiancan Zhang \\ Nanchang Institute of Science \& Technology, Nanchang, Jiangxi, 330000
}

Keywords: technical study; college psychological crisis; management skill

\begin{abstract}
By strengthening the mental health education for college students, the psychological knowledge of college administrators and moral education workers and the ability to prevent psychological crisis can be improved. Through patient and meticulous dialogue and exchange activities, the psychological crisis formed by college students can be channeled and resolved. And the use of drugs for treatment and other measures can improve the prevention and treatment of college students' psychological crisis.
\end{abstract}

\section{Introduction}

The psychological and behavioral abnormalities caused by college students' psychological crisis events have increasingly attracted the attention of colleges and universities. College students are special groups. Their inner world is relatively complex, with higher ideological realm and psychological needs. Most of them are far away from home and relatives, living in a strange social environment, interpersonal relationships need to be rebuilt, yearning for love and worry, and academics. Stress and frustration, the stagnation of employment, and poor family economic conditions can all bring tremendous psychological pressure. College students are in the stage of psychological development, and conflicts of various values during the social transformation period may cause them to be in a state of confusion of psychology, emotions and behaviors. These external pressures and inner chaos make their minds unbalanced and unable to rely on them. Their own strength returned to normal in a short period of time, and they were in crisis. Studies have shown that college students have higher suicide rates than general youth suicide rates.

\section{The Causes of College Students' Psychological Crisis}

The cause of psychological crisis in college students is the occurrence of crisis events. Crisis events are usually negative life events that occur around college students, such as exams, grades, and graduations; family problems such as loss of love, bad interpersonal relationships, family financial difficulties, family changes, and other emotional problems such as depression and anxiety. , employment is frustrated and so on. These negative life events can lead to psychological crisis.

Of course, negative life events do not necessarily lead to a psychological crisis for college students. For example, the same academic failure or frustration in love, some students are more and more frustrated, and some students are devastated. In fact, the specific perception of crisis events leads to the suffering of the parties. That is to say, in the same crisis, some students grow up in the process of coping, and some students fall into panic, helplessness, or even self-injury or injury. The key to this is the student's perception and interpretation of negative life events. For example, after encountering the exam, some students actively look for reasons for hanging out, suddenly realize that they spend too little time on learning, or that the learning method is not correct, etc., actively take remedial measures, and finally make up the exam, and learn more. Work harder and care harder. Some students are in a panic. They think that this time they will hang up the subject, and they will hang up in the future. If they are too many, they will not be able to graduate. If they can't graduate, they will not find a good job. Objects, this life is over, in this negative cognitive mode, unable to concentrate on learning, students fall into panic, anxiety, nervousness, which may lead to psychological crisis.

Psychologist Caplan. G believes that when a person faces a difficult situation, the previous 
response to the problem is not enough to deal with the immediate predicament, that is, he must face the dilemma beyond his ability to cope, this person will have a temporary psychological disorder and psychological crisis status. Therefore, coping ability has an important impact on students' psychological crisis. In general, when individuals encounter negative life events, they usually adopt two main types of coping methods: problem solving and emotional coping. When the individual finally solves the problem through various efforts and seeks external support, the crisis is successfully lifted. When individuals still do not solve the problem through the above efforts, they need to use emotional coping methods to deal with psychological crisis. Coping styles are divided into mature coping styles and immature coping styles according to their preferences. The mature coping style shows a mature and stable personality trait and behavior in life, including coping with problems and help. Immature coping styles show a retreating personality in life, lack of stability in emotions and behaviors, including retreat, self-blame, fantasy and other coping styles. When college students encounter negative sexual life, if they adopt immature coping styles, they are not conducive to coping with difficulties and are prone to psychological crisis. If mature coping styles are adopted, it will help relieve mental stress and help students finally solve problems successfully. Adjust your mental state and protect your mental health.

Social support is an important factor affecting people's social life. Social support can be divided into two categories in nature. One is objective support. Such support is visible or practical, including direct material assistance, existence and participation of group relationships (including stable relationships such as family, Friends, classmates, etc., or unstable social connections such as informal groups, temporary social communication, etc. and availability. The other type is subjective support. This kind of support is the support experienced or emotionally felt by the individual. It refers to the emotional experience and satisfaction degree of the individual being respected, supported and understood in society, which is closely related to the subjective feeling of the individual. . Most scholars believe that good social support is conducive to physical and mental health, while the existence of inferior social relations impairs physical and mental health. On the one hand, social support provides protection for individuals under stress, that is, buffering stress, and on the other hand, it is important to maintain a general good emotional experience.

\section{Intervention Method of College Students' Psychological Crisis}

All major colleges and universities should pay attention to the psychological crisis management of college students, set up corresponding psychological counseling rooms, and improve the crisis management institutions. First, crisis management agencies need to be equipped with professional and responsible full-time teachers. The full-time teacher shall be a fixed staff member of the organization, and shall be in the resident institution and accept the consultation or help from the whole school. The part-time teacher may be concurrently qualified by the counselor with relevant qualifications, and is responsible for the occasional investigation and psychological counseling of the students under management. Secondly, it is necessary to establish a management plan for college students' psychological crisis, organize lectures on mental health education, set up psychological crisis education courses, add college students' attention to mental health and correct understanding, carry out active and effective psychological crisis prevention publicity and education, and urge all majors to carry out Healthy and active physical fitness activities to enhance students' spare time. Thirdly, develop an effective crisis management monitoring mechanism, regularly use electronic questionnaires, paper questionnaires, etc. to monitor and evaluate the mental health of college students. At the same time, make assessments and predictions of possible crisis situations, and put forward emergency prevention opinions and establish emergency plans. Unscheduledly organize teachers and students to carry out emergency drills and gradually correct the plan. Finally, establish a sound crisis management team, select professionals to set up crisis incident handling centers, and improve the crisis emergency contact database. We can actively coordinate and integrate the use of resources inside and outside the school, handle crisis events efficiently and properly, and ensure that the normal learning life of the campus can be restored as soon as possible after the crisis is handled. 
First, colleges and universities should actively strengthen the establishment and management of student unions and various associations, increase capital investment, strengthen college students' organizations, and guide students to actively participate in student unions and various associations. Through the student self-management system, on the one hand, strengthen students' spare time, and enrich Colorful leisure activities to eliminate students' negative and empty psychological anxiety, on the other hand, help schools manage students and strengthen communication between schools and students. Student unions and societies are self-management systems. Many students with active work, excellent academic performance, and strong organizational and coordination skills serve as cadre positions. Through these students, students can enhance their understanding of students' psychological crisis. At the same time, it can also help professional teachers and counselors to guide and treat students with psychological problems. The second is to incorporate the psychological crisis early warning and treatment of students into the regular work of the student unions and associations, and conduct targeted training for student unions, association cadres, student party members and cadres, and actively organize cadres to participate in emergency drills, participate in the revision of the plan, and use students. The strength of cadres is to carry out psychological state monitoring and psychological crisis management among students. At the same time, when crisis events occur, the strength of student cadres is integrated in time, and crisis management is organized.

First, professional institutions and counselors, such as counseling rooms, should establish an electronic information archive for students with psychological problems and abnormal performances, and collect basic information about the complete students, including learning situation, family situation, parental contact information, and roommate contact. Ways, feelings, etc., make detailed records of the psychological situations that students have experienced. The second is to monitor the psychological state of students through the network monitoring platform. For example, through the new media such as Weibo, WeChat, QQ Space, Renren.com and Post Bar Forum, the psychological state of students is monitored, and the psychological changes of students are fully grasped in time. crisis. The third is to actively establish a psychological counseling interactive platform, WeChat public platform and other network consulting institutions to facilitate psychological counseling for students, and also use the network platform to carry out various types of psychological crisis prevention and treatment, strengthen students' psychological crisis education, and guide Students build awareness of crisis management.

Counselors are the most important teaching power for college students to receive ideological education and counseling during their school years. They are also the teachers who have the closest contact with students and the most understanding of the students' psychological state. They can get the trust and confidence of students, and they are easy to be healthy and active. The idea is conveyed to college students and plays a vital role in the handling of psychological crisis events. Therefore, the role of counselors is not negligible. First of all, the counselor should have a strong sense of responsibility and good psychological quality. Counselors should first face the psychological crisis of college students, study psychological education of college students as an important topic, actively strengthen communication with students, and strive to establish a trusting relationship with students through face-to-face communication and online chat and communication. Listen appropriately and help in a timely manner to guide students to be positive. At the same time, the counselor needs to have a good psychological quality. When the student has a psychological crisis, the counselor must be calm and self-sufficient, and resist the pressure to relieve the students' panic, so as to ensure that the incident is obtained. Order, proper handling. Second, the counselor should give full play to the role of the communicator and the implementer. After the incident, the counselor needs to respond quickly, understand the comprehensive event information as much as possible, take decisive response measures, inform the school leaders in a timely manner, and notify the parents of the parents to report the police if necessary. In the process, the counselor should strengthen contact with the parents and the school, and coordinate the opinions of all parties to cooperate with relevant departments. Finally, the counselor should give full play to the role of the comforter. Students should be given constant care, help them coordinate the relationship with 
classmates and roommates, and create a warm and harmonious learning environment to help students recover from crisis events as soon as possible. At the same time, counselors should constantly sum up and extract experience in their work, strengthen their awareness of crisis events, put early warning of crisis events in a more important position, and establish a normal management mechanism and educational mechanism.

\section{Conclusion}

Under the complicated and ever-changing social background, colleges and universities should adopt scientific and effective methods to correctly prevent, cope with and deal with the psychological crisis of college students, and create a good environment for the healthy growth of college students.

\section{References}

[1] Wang Shitang. The Causes and Intervention Strategies of College Students' Psychological Crisis [J]. Jiangxi Education and Research, 2007 (1).

[2] Yang Shengyong. Causes and countermeasures of college students' psychological crisis [J]. Journal of Guizhou Nationalities University, 2006 (4).

[3] Rui Rui. Analysis of the Causes of College Students' Psychological Crisis and Exploration of Crisis Intervention [J]. Journal of Southwest University of Science and Technology (Philosophy and Social Sciences Edition), 2006 (2).

[4] Fan Fuzhen. University mental health education research [M]. Beijing: Tsinghua University Press, 2002.

[5] Yang Honghui. On College Students' Mental Health and Physical Exercises [J]. Shandong Sports Science and Technology, 2008 (4). 